\title{
¿Go-Shops en Lima?
}

\section{Carlos Granda Boullón**}

En el presente artículo, el Profesor Carlos Granda explica el concepto de Go-Shop. Para ello, explica los diversos beneficios económicos que posee esta cláusula contractual y qué tan conveniente sería traer aquel sistema a nuestro país.

Abogado por la Pontificia Universidad Católica del Perú. Master en Derecho por The University of Michigan Law School. Profesor de Derecho Civil y de Fusiones y Adquisiciones de la Facultad de Derecho de la Pontificia Universidad Católica del Perú. Socio de Estudio Osterling Abogados.

** Quiero agradecer a Mareike Krenning, Viviane Meunier, Alonso Barreda, Javier Fernández-Concha y a mis alumnos del curso de Fusiones y Adquisiciones de la Facultad de Derecho de la Pontificia Universidad Católica del Perú (semestre 2013-II) por sus contribuciones a este artículo. 


\section{¿Go-Shops en Lima?}

\section{INTRODUCCIÓN}

Go-Shop es un término que hace referencia a un tipo de cláusula que puede usarse en un contrato de compraventa de acciones. Mediante este pacto, los vendedores adquieren la prerrogativa de promover ofertas de adquisición de terceros una vez que han firmado un contrato de compraventa de acciones con un comprador. Así, en el mercado de los Estados Unidos de América ("EUA" en adelante), un vendedor, representado por el directorio de la compañía objetivo en todos los casos en que ésta es pública o listada y en la mayoría de los casos cuando es privada, obtiene entre 20 y 60 días, aproximadamente, para buscar activamente ofertas de terceros por la compañía, luego de lo cual y de no haber tenido éxito se produce la fecha de cierre del contrato de compraventa de acciones ${ }^{1}$ y se vende por lo tanto al comprador con quien se había firmado el contrato.

Este tipo de acuerdo contractual permite verificar en el mercado cuál es el máximo valor que un vendedor puede obtener por la compañía una vez firmado el contrato, por consiguiente no tiene lugar cuando antes de firmar el contrato el vendedor promueve un concurso privado. Ésta última es una posibilidad, a diferencia de los Go-Shop, sí ya ha sido utilizada por algunos vendedores en el mercado peruano. Aún no se ha convertido en una tendencia sin embargo; solamente me animaría a decir que la banca de inversión y al menos un estudio de abogados, que yo sepa, ya han promovido este tipo de creación de ofertas competitivas en la venta de empresas.

Los Go-Shop no se usan en el mercado legal de fusiones y adquisiciones peruano. Ello es así porque responden a una realidad que no existe en nuestra economía (mercado bursátil de cambio de control desarrollado), y por lo tanto nuestro derecho de Fusiones y Adquisiciones no ha tenido que desarrollar una respuesta para este tipo de realidad, como vamos a explicar en la sección

\footnotetext{
En los contratos de compraventa de acciones las partes pueden pactar que los efectos traslativos de propiedad de las acciones queden suspendidos hasta que se produzcan determinados hechos $y, 0$, que se realicen ciertos actos por parte del vendedor $y, 0$, el comprador. El nombre que se asigna a este tipo de reglas privadas es "Condiciones Precedentes". Cuando se sujeta la eficacia total del contrato de compraventa de acciones a la verificación de Condiciones Precedentes, se incluye también una regulación del "cierre", o momento en el que las partes se obligan a realizar determinados actos que producirán los efectos traslativos de propiedad y por lo tanto la eficacia plena del contrato de compraventa de acciones. Este segundo momento se regula bajo la denominación "Fecha de Cierre" o simplemente "Cierre".
} 
segunda de este artículo; pero también porque no se ha producido un espacio de discusión en el que se analice la utilidad que la aplicación de esta figura puede tener para adquisiciones locales, como vamos a ver en la cuarta sección de este texto de investigación.

La propuesta de este artículo es que los Go-Shop, habida cuenta de que estoy de acuerdo con que pueden generar beneficios económicos para los vendedores, podrían utilizarse en nuestro mercado en transacciones o deals que se produzcan en determinadas circunstancias que se explican en la sección cuarta de este artículo. Esta propuesta puede ser incluso más valiosa una vez que nuestro mercado de control corporativo se vuelva más activo, como se viene pronosticando que va a ocurrir en particular a propósito de la mayor actividad que pretenden alcanzar firmas internacionales que se dedican al negocio de private equity o de administración de capital de riesgo, si se quiere, en nuestro país.

\section{II. DELIMIATCIÓN Y FUNCIÓN EN EL CONTRATO DE
COMPRAVENTA DE ACCIONES}

\section{II.1 Origen}

Nadie se ha atribuido la paternidad de este tipo de provisión contractual, o al menos nadie que haya podido rastrear. No hay en esta historia, como sí en la historia del Poison Pill, un Martin Lipton a quien atribuir la creación, defensa y financiamiento del desarrollo académico de un tipo de estrategia concreta en el mercado de fusiones y adquisiciones. Lo que puedo decir es que es una provisión contractual que tiene origen en los EUA. Tampoco la ciudad de origen está clara. Es muy posible que haya sido Nueva York, que es el mercado más grande de fusiones y adquisiciones de EUA y del globo, pero a la fecha no hemos encontrado documentos que nos permitan afirmar esto con completa seguridad.

Técnicamente sin embargo, en Revlon, Inc. c. MacAndrews \& Forbes Holdings, Inc. (Revlon) sí se puede considerar el punto de origen del uso reciente de los Go-Shop en la medida que crea nuevos deberes en el directorio de las sociedades objetivo, o Targets como le vamos a llamar aquí, de EUA; y con ello determina la aparición de nuevos mecanismos de tutela de los intereses de los accionistas en escenarios de ventas de empresas ${ }^{2}$. Entre esos mecanismos están los Go-Shop. Como hemos anticipado aquí, en las sociedades listadas americanas el directorio conduce el proceso de venta de una empresa, y esto

Christina Sautter, Shopping During Extended Store Hours: From No Shops to Go-Shops. Brooklyn Law Review, Vol 73, 2008. Página. 525. 
no tiene que ver con el hecho de que puedan haber individuos que conduzcan el proceso de venta en la práctica, sino con que legalmente es el directorio el que toma las decisiones de venta y tiene responsabilidad, no exclusiva, por los daños que una venta pueda producir a los accionistas. En este contexto legal, a través de Revlon la Corte Suprema de Delaware crea en 1986 el deber fiduciario en cabeza del directorio de llevar a cabo todos los actos que sean necesarios para maximizar el precio que puedan obtener los accionistas en la venta. Más allá de eso, Revlon expresamente se refiere a la generación de mecanismos de ofertas competitivas como un medio para alcanzar este objetivo.

\section{II.2 Delimitación de la figura}

Los Go-Shop son provisiones contractuales convencionales. Esto quiere decir que son acuerdos que pueden o no convenir incluir las partes en los contratos de compraventa de acciones.

Nuestro sistema legal permite la adopción de este tipo de acuerdos en aplicación del Principio de Autonomía Privada, regulado por los artículos $\mathrm{V}$ del Título Preliminar, 1354, 1355 y 1356 del Código Civil y 62 de la Constitución Política del Perú. El citado principio permite a las partes de un contrato establecer reglas privadas sin más limitaciones que las previstas en las normas imperativas de nuestro sistema jurídico, en lo que constituyan las buenas costumbres en cada momento y en el orden público que el Estado tutele versus lo que se vaya a disponer en el contrato o provisión contractual. No habiendo una norma imperativa que impida solicitar ofertas de compra de una empresa en un contexto en el que el vendedor ya ha firmado un contrato de compraventa de acciones pero no se ha producido el cierre del mismo, y por lo tanto en circunstancias en que las disposiciones del contrato aún no se han convertido en vinculantes al menos en lo que se refiere a la transferencia de propiedad de las acciones, es posible que las partes lleguen a este tipo de acuerdo. Las buenas costumbres y el orden público no tienen incidencia en este tipo de provisión contractual.

Cabe hacer una aclaración, a partir de la idea de uno de mis alumnos del curso de Fusiones y Adquisiciones, Sergio García Long, en relación con la aplicabilidad del artículo 1582 del Código Civil a los Go-Shops. Este artículo impide la reversión de la compraventa en favor del vendedor en dos supuestos determinados. El inciso 1 permite al vendedor obligar al comprador a rescindir el contrato si encuentra alguien que dé más por el bien luego de haberlo adquirido; así, en este supuesto la norma dispone que el comprador debe devolver el bien al vendedor. El inciso 2 impide que el vendedor pueda pactar 
que tiene preferencia en caso el comprador decida vender el bien luego de adquirirlo. Sin perjuicio de los posibles comentarios que merezca el empleo de la categoría jurídica "rescisión" aquí, y de los cruces entre el derecho de preferencia que regula la Ley General de Sociedades y el inciso 2 de este artículo por ejemplo, que vale la pena comentar, pero no aquí; conviene a los propósitos de este artículo aclarar que la norma en cuestión no es aplicable a los Go-Shop por cuanto ésta es una regulación contractual que surte efectos antes de que se produzca la transferencia de propiedad, que surte efectos en otras palabras entre la fecha de firma y la fecha de cierre, mientras que la norma bajo comentario regula supuestos que se producirín después de producida la transferencia de propiedad.

Claudia Canales Torres, sustentando su opinión en la de Max Arias Schreiber Pezet, opina que el inciso 1 del artículo en cuestión no es conveniente por la inseguridad jurídica que genera en el comprador; $y$, esta vez individualmente, que la prohibición del inciso 2 es acertada porque restringe la libertad de contratar, que es una de las aristas del principio de autonomía privada, y desalienta el "tráfico contractual". ${ }^{3}$ Yo pienso que, no habiendo un interés que (i) se presente siempre en este tipo de supuesto de hecho y (ii) que convenga tutelar, ambos pactos deberían ser permitidos en la medida en que, como hemos dicho, no protegen per se una u otra posición jurídica y las partes deberían ser libres de poder llegar a estos acuerdos si en cada situación contractual estiman que satisface sus intereses. El pacto de preferencia por lo demás, para el caso de acciones, es especialmente conveniente en sociedades que se forman con la idea de restringir el acceso a la condición de accionista; como concluyen categóricamente todas las legislaciones de sociedades que he tenido la oportunidad de leer.

Típicamente, en los mercados de EUA y Canadá, una cláusula de este tipo consiste en lo siguiente ${ }^{4}$ :

- Permitir a los vendedores buscar posibles compradores; delimitar el universo de personas $y, 0$, empresas a las que se puede solicitar nuevas ofertas; permitir entregar información de la compañía que permita a los destinatarios de las invitaciones a ofertar valorizar la misma; y solicitar que hagan llegar ofertas de compra del Target.

3 Claudia Canales Torres. Pactos Nulos en el Contrato de Compraventa. Código Civil Comentado, Tomo VIII, Gaceta Jurídica, 2007. Páginas. 199 y 201.

$4 \quad$ Richard Willoughby, Michael Amm y Leslie McCallum. Go-Shop Clauses in the United States and Canada: Window Dressing or a Useful Market Check? CCA Corporate Counsel Directory and Yearbook, Sexta Edición, 2008. 
- Otorgar un periodo para realizar las actividades previstas en el numeral que antecede. En el mercado de fusiones y adquisiciones de EUA este periodo se estima que estriba entre los 20 y 60 días.

- Establecer las condiciones en que los vendedores pueden aceptar las ofertas de los terceros que hayan respondido positivamente a la búsqueda de los vendedores. La principal condición es que la nueva oferta sea superior a la oferta del comprador que ya ha firmado el contrato de compraventa de acciones con el vendedor. El precio a pagar por el comprador inicial se convierte entonces en un piso para las subsiguientes ofertas.

- Establecer un pago a favor del comprador inicial en caso el vendedor obtenga una mejor oferta. Este pago es uno de los tipos de Termination Fees que pueden incluirse en los contratos de compraventa de acciones.

- Otorgar al comprador inicial el derecho a modificar su oferta para equipararla a la mejor oferta que obtengan los vendedores $y$, en consecuencia, cerrar la transacción (Matching Rights).

\section{II.3 Función en el contrato de compraventa de acciones}

Los Go-Shops se clasifican dentro del género denominado mecanismos de protección de la transacción o Deal Protection Devices como se les conoce en su jurisdicción de origen. Sin embargo, más allá de proteger jurídicamente la eficacia de estos acuerdos, es decir, más allá de tener una función normativa o legal, tienen también como vamos a ver en la tercera sección de este artículo una función económica. Lo último es porque pueden ayudar a una mejor formación del precio de una empresa, al permitirle al vendedor crear un mercado competitivo de ofertas.

La idea de proteger una transacción surge a partir de la preocupación de los participantes de esta industria por evitar que los contratos sean considerados inválidos e ineficaces en las cortes del los EUA por causa de reclamos de accionistas que puedan considerar que la transacción afecta sus intereses. Así, un accionista puede cuestionar una transacción en EUA si considera que los directores no actuaron efectivamente en su favor al decidir recomendar la venta y llevarla a cabo en la práctica.

En el Derecho de los EUA, los directores deben cumplir con un set de deberes en el escenario de las fusiones y adquisiciones. Con el objeto de dar una idea del alcance de la regulación de la conducta de los directores en este contexto, y sin perjucio de otras decisiones que han impactado recientemente la conciencia del mercado respecto de lo que se espera de los directores en contextos como 
éste en EUA para que las transacciones no sean declaradas ineficaces, total o parcialmente, por las cortes; presentamos al lector el resumen que sigue. Estos deberes incluyen el Deber de Equidad, por el que los actos de los directores deben reflejar equidad en el precio o una equidad o justicia substancial, y equidad en el procedimiento que se haya llevado a cabo para determinar el precio, o una equidad procedimental ${ }^{5}$; el Deber del Buen Juicio de Negocios ${ }^{6}$, que les impone tomar una decisión basada en información completa y oportuna, que además sea razonable en el contexto de negocios en que se produzca; el Deber Unocal?, por el que en contextos de adquisiciones hostiles, los deberes del directorio se extienden a demostrar una correcta evaluación del riesgo que corría el Target de ser adquirido por un recio desfavorable, y que la medida defensiva era apropiada para mitigar específicamente dicho riesgo; el comentado Deber Revlon ${ }^{8}$, por el que los directores tienen que demostrar que llevaron a cabo medidas adecuadas para maximizar el precio que podían obtener los accionistas; y, el Deber Unitrin ${ }^{9}$, por el que el directorio no puede adoptar una medida defensiva draconiana, que para las cortes de Delaware son medidas que resultan coercitivas de la venta o preclusivas de la misma.

Entre las figuras que se utilizan para evitar que se pueda argumentar, una vez firmado y, o, cerrado el contrato de compraventa de acciones, que el mismo no contiene mecanismos que permitan a los directores el cabal ejercicio de sus deberes fiduciarios están el pacto de efectuar un pago por el ejercicio de la prerrogativa de terminar unilateralmente el contrato de compraventa de acciones (Break Up Fees o Walk-Away Fees); la prohibición de solicitar nuevas ofertas conjugada con la permisión de aceptar nuevas ofertas que no hayan sido solicitadas, si se producen (No-Shop y Window Shop más Fiduciary Outs); $y$, el derecho del comprador de equiparar la oferta inicial a posibles mejores ofertas que se produzcan antes del cierre del contrato de compraventa de acciones (Matching Rights). Esta última estrategia se suele usar conjugada con Go-Shops y No-Shops por ejemplo.

$5 \quad$ Weinberger c. UOP, Inc. 457 A.2d 701 (Del. 1983).

6 Smith c. Van Gorkon. 488 A.2d 858, 3 EXC 112 (Del. 1985)

$7 \quad$ Unocal Corp. c. Mesa Petroleum. 493 A.2d 946 (Del. 1985)

8 Revlon, Inc. c. MacAndrews \& Forbes Holdings, Inc. 506 A.2d 173 (Del. 1985)

9 Unitrin Inc. C. American General Corp. 651 A.2d 1361 (Del. 1995). 


\section{FUNCIÓN ECONÓMICA}

Más allá de la función jurídica que como hemos visto en la sección que antecede pueden tener los Go-Shops en el sistema legal de los EUA, la academia de este país se ha preguntado también si en efecto los Go-Shops (i) permiten crear un mercado competitivo de ofertas y si (ii) este mercado competitivo de ofertas produce beneficios a los accionistas vendedores mayores que los que obtienen los compradores y el mercado en general cuando no existen subastas privadas al inicio de la venta o Go-Shops una vez ue se ha firmado el contrato pero no se ha cerrado.

Al respecto, Easterbrook y Fischel $^{10}$ argumentan que facilitar ofertas competidoras en escenarios de compraventa de empresas no es deseable puesto que desalientan la búsqueda de Targets por parte de potenciales compradores, al reducir potencialmente el retorno que éstos obtendrían en el mercado de adquisiciones de empresas a cambio de su actividad de búsqueda de Targets. La ganancia de estos últimos se reduciría en la medida en que estos autores sostienen que crear una competencia de ofertas favorece el incremento de las primas que se pagarían por las empresas. Desde esta óptica, el sistema debe favorecer a los potenciales compradores puesto que éstos agentes económicos garantizan en este escenario la premisa económica conforme a la cual conviene a la generación de riqueza general en una sociedad que los recursos económicos sean transferidos a aquellos que les asignan un mayor valor a su uso. Los potenciales compradores, al identificar empresas subvaluadas por sus propietarios y pretender adquirirlas para obtener un mayor valor de ellas, estarían contribuyendo a la generación de riqueza general en una sociedad; y esto en opinión de estos autores debe ser preferido frente a la posibilidad de obtener mayores ganancias que tengan los vendedores en una transacción específica mediante el uso de mecanismos que fomenten la competencia de ofertas. Esta posición, explican Easterbrook y Fischel, fue adoptada por la Corte Suprema de los Estados Unidos en su fallo en el caso Edgar c. MITE Corp. ${ }^{11}$

Frente a esta corriente de pensamiento, Lucian Bebchuck ${ }^{12}$ sostiene que la mayor frecuencia en adquisiciones que se produciría al permitirle a los

10 Frank Easterbrook y Daniel Fischel, Auctions and Sunk Costs in Tender Offers. Stanford Law Review, Vol. 35, 1982. Páginas 1 y siguientes.

11 Edgar C. MITE Corp., 102 S. Ct. 2629, 2642 (1982).

12 Lucian Bebchuck. The Cae for Facilitating Competing Tender Offers: A Reply and Extension. Stanford Law Review, Vol. 23, 1982. Páginas. 23 y siguientes. 
potenciales compradores obtener mayores ganancias como fruto de su labor de búsqueda y adquisición de compañías no genera beneficios económicos generales mayores que los que genera el fomento de ofertas competidoras. En su opinión, tanto desde la perspectiva del fomento de la riqueza social general, como del fomento de la generación de riqueza empresarial general, es deseable que los accionistas encuentren el potencial comprador que les de el mayor valor por sus acciones y las empresas en general. Propugnar la irrestricta posibilidad de generar ofertas competidoras, por tanto, para este autor, no tiene un efecto substancial comprobado en el decrecimiento de los costos de búsqueda de los potenciales compradores por cuanto estas compañías, sobre todo en mercados con industrias de banca de inversión y private equity desarrolladas, igual asignan recursos a la búsqueda de empresas subvaluadas; ni en el decrecimiento del número de adquisiciones, lo que podría llevar a pensar que al permitir este tipo de figuras se genera una desaceleración del mercado de fusiones y adquisiciones, con las consecuencias perjudiciales que esto tiene para la correcta asignación de precios a las acciones y el incentivamiento de reemplazo de administradores cuya labor hace decrecer la rentabilidad y con ello el valor mismo de las empresas.

El profesor Guham Subramanian aportó mucho a esta discusión económica de abogados, al publicado una medición matemática de los efectos que los GoShops tienen en el mercado de fusiones y adquisiciones ${ }^{13}$. Este profesor encontró, estudiando la industria de private equity en un periodo determinado y basándose en información estadística sobre deals que publican en los EUA empresas como MergerMetrics, (i) que los Go-Shops generan mayor búsqueda de Targets, (ii) los Go-Shops en contextos en los que no se hizo una subasta privada al inicio del deal resultan en el hallazgo de un comprador que oferta más por las acciones en un $17 \%$ de las veces, y (iii) que los accionistas de Targets reciben aproximadamente $5 \%$ más por sus acciones cuando optan por incluir Go-Shops en vez de incluir No-Shops en sus contratos de compraventa de acciones. Sobre la base de estos hallazgos económicos el autor recomienda a las cortes de Delaware permitir los Go-Shops, desde que considera que constituyen un mecanismo que permite a los directores encargados de la venta satisfacer el Deber Revlon, o maximizar la riqueza que puedan obtener los vendedores de un Target. Subramanian se refiere a las cortes de Delaware

13 Guhan Subramanian. Go-Shops vs. No-Shops in Private Equity Deals: Evidence and Implications. The Business Lawyer, Vol. 63, 2008. Páginas. 729 y siguientes. 
porque son las que más incidencia tienen en el mercado de fusiones y adquisiciones de los EUA. Esto es así porque una gran cantidad de compañías de los EUA busca constituirse en Delaware precisamente por sus avanzados y predecibles Derecho Societario y Derecho de las Fusiones y Adquisiciones.

\section{POSIBLES APLICACIONES EN NUESTRA PLAZA}

El hecho de que, como hemos visto en la sección 3 de este artículo, los GoShops sean mecanismos que permitan mejorar el precio y, o, las condiciones que en general pueden obtener los vendedores en una compraventa de acciones, sugiere que este tipo de regla privada puede ser conveniente incluso en contextos en los que no se exige legalmente que los directores maximicen los beneficios para los vendedores.

Esto es, desde la perspectiva normativa el uso de Go-Shops en la plaza local no reviste ninguna utilidad porque no existen los mismos constreñimientos legales en nuestro sistema, amén de que los procesos de venta de empresas en nuestro país son dirigidos por los accionistas mismos. Lo último es cierto porque el mercado secundario de acciones en el Perú aún no es lo suficientemente grande como para que podamos predicar que se produce en el mismo el problema de desalineamiento entre los intereses de los administradores y de los accionistas (Agency Theory) que se produce en los mercados de diversos estados de los EUA.

Sin embargo, la evidencia económica consultada permite afirmar que, cuando es posible negociar Go-Shops en un contrato de compraventa de acciones, (i) resultan beneficiosos para los vendedores y (ii) no tienen efectos sistémicos perjudiciales, como podrían ser (A) disminuir significativamente los incentivos de búsqueda de empresas objetivo, al reducir las ganancias de aquellos que participan del negocio de adquisición de empresas, o, (B) reducir el número de transacciones y por lo tanto la fluidez y la capacidad de asignar a las acciones el mayor valor que esté dispuesto a darle un participante del mercado de fusiones y adquisiciones de empresas.

Frente a esta evidencia inicial, creo que es conveniente explorar a qué vendedores es posible recomendarles la negociación de una clausula Go-Shop. Sobre todo esto es realista cuando éstos sean aproximados por inversionistas o adquirentes financieros (bancos de inversión o firmas de private equity), que es posible no estén dispuestos a reconocer el mismo beta que estaría dispuesto a aceptar para formar el precio un competidor estratégico. 